\title{
PEMANFAATAN PENCAHAYAAN ALAMI PADA RENOVASI RUMAH TINGGAL MENGHADAP ARAH BARAT
}

\author{
Ibayasid $^{1)}$, Sujiati Jepriani' ${ }^{2)}$, Hatta Musthafa A.P ${ }^{3)}$,Bhanu Rizfa Hakim ${ }^{4, ~}$ ) \\ 1,2,3,4 Politeknik Negeri Samarinda \\ Email: ㅁhanuarsitek@gmail.com
}

\begin{abstract}
The need for housing is very rapid, especially the type of house growing with several choices of area, namely types 21, 27, 36, 45 to $120 \mathrm{~m} 2$. In the growing house will be provided land for homeowners to develop the house so it is more feasible. The concept of housing provided by the developer is sometimes incompatible with the concept of utilizing natural lighting because it only emphasizes attractive design and number of units. For this reason, it is necessary to provide a reference for homeowners as a strategy to renovate buildings facing the west so that the utilization of natural lighting remains optimal and meets the measurement of comfort visually. The study will analyze the average lux value or Daylight Levels avarage of natural lighting resulting from the amount of light openings. The analysis will be done is the average value of natural lighting from the location strategy and the amount of light aperture in producing quality lighting in space. The kitchen room and family room are spaces with a high level of activity that require optimal lighting. The most optimal lighting level is the opening type of model 1 with 10\% opening in the west, 10\% opening in the roof, and $50 \%$ in the east. The resulting lighting level is 998.58 lux in clear sky conditions and 849 lux overcast conditions.
\end{abstract}

Keywords: natural lighting, residential, visual comfort

\begin{abstract}
ABSTRAK
Kebutuhan rumah tinggal sangat pesat, terutama tipe rumah tumbuh dengan beberapa pilihan luasan, yaitu tipe 21, 27, 36, 45 hingga 120m2. Pada rumah tumbuh akan disediakan lahan bagi pemilik rumah untuk mengembangkan rumah sehingga lebih layak. Konsep hunian yang disediakan oleh pengembang terkadang tidak sesuai terhadap konsep pemanfaatan pencahayaan alami karena hanya menekankan pada desain menarik dan jumlah unit. Untuk itu diperlukan acuan bagi pemilik rumah sebagai strategi untuk melakukan renovasi bangunan menghadap barat agar pemanfaatan pencahayaan alami tetap optimal dan memenuhi takaran kenyamanan secara visual. Penelitian akan menganalisis nilai lux rata-rata atau Daylight Levels avarage dari pencahayaan alami yang dihasilkan dari besaran bukaan cahaya. Analisis yang akan dilakukan adalah nilai rata-rata pencahayaan alami dari strategi perletakkan dan besaran bukaan cahaya dalam menghasilkan kualitas penerangan dalam ruang. Ruang dapur dan ruang keluarga merupakan ruang dengan tingkat aktivitas tinggi sehingga memerlukan penerangan yang optimal. Tingkat pencahayaan yang paling optimal adalah tipe bukaan model 1 yaitu dengan bukaan 10\% bagian barat, 10\% bukaan bagian atap, dan 50\% bagian timur. Tingkat pencahayaan yang dihasilkan adalah 998,58 lux pada kondisi clear sky dan 849 lux kondisi overcast.
\end{abstract}

Kata Kunci : pencahayaan alami, rumah tinggal, kenyamanan visual 


\section{PENDAHULUAN}

Indonesia merupakan salah satu negara yang dilewati garis khatulistiwa, sehingga paparan cahaya matahari dapat dirasakan sepanjang hari dan memiliki potensi untuk dimanfaatkan sebagai sumber cahaya didalam rumah tinggal maupun gedung. Dua alasan utama penggunaan cahaya alami, penghematan energi serta pencahayaan alami sebagai bagian dari kesehatan [1].

Kebutuhan rumah tinggal sangat pesat, terutama tipe rumah tumbuh dengan beberapa pilihan luasan, yaitu tipe 21, 27, 36, 45 hingga $120 \mathrm{~m} 2$. Pada rumah tumbuh akan disediakan lahan bagi pemilik rumah untuk mengembangkan rumah sehingga lebih layak. Konsep hunian yang disediakan oleh pengembang terkadang tidak sesuai terhadap konsep pemanfaatan pencahayaan alami karena hanya menekankan pada desain menarik dan jumlah unit. Desain setiap rumah tipikal sehingga konsumsi pencahayaan alami akan berbeda bagi rumah yang menghadap timur dan rumah yang menghadap barat. Hunian yang tersedia cenderung memiliki orientasi bukaan pencahayaan alami pada bagian depan dan belakang karena bagian samping berbatasan dengan hunian lain.

Masyarakat Indonesia cenderung tidak memanfaatkan penerangan di siang hari (daylighting) dikarenakan pengetahuan yang terbatas terhadap cara pemanfaatan pencahayan siang hari (daylighting) [2]. Perancangan penerangan alami yang tepat adalah memasukkan matahari berupa cahaya pantulan kedalam ruangan sesuai dengan standar dan kebutuhan. Cahaya dan terang alami merupakan prasyarat penting dalam penerangan alami. [3]

Permasalahan tersebut menyebabkan rumah yang menghadap barat akan panas namun disisi lain cahaya matahari harus tetap dimanfaatkan sebagai sumber cahaya penerangan pada siang hari. Untuk itu diperlukan acuan bagi pemilik rumah sebagai strategi untuk melakukan renovasi bangunan menghadap barat agar pemanfaatan pencahayaan alami tetap optimal dan memenuhi takaran kenyamanan secara visual.

\section{METODE PENELITIAN}

Penelitian akan mengkaji strategi pemanfaatan pencahayaan alami melalui besaran bukaan pada proses renovasi rumah tinggal tipe $27 \mathrm{~m} 2$. Renovasi rumah tinggal dimaksud adalah penambahan ruang dapur dan ruang keluarga.

Penelitian akan menganalisis nilai lux atau Daylight Levels average (nilai kuat cahaya) dari pencahayaan alami yang dihasilkan dari besaran bukaan cahaya. Analisis yang akan dilakukan adalah nilai rata-rata pencahayaan alami dari strategi perletakkan dan besaran bukaan cahaya dalam menghasilkan kualitas penerangan dalam ruang. Metode yang digunakan adalah analisis berdasarkan model simulasi computer melalui software Ecotect Analysis 2011.

\section{Model Studi}

Penelitian mengambil data yang dihasilkan dari software Ecotect Analysis. Rumah yang menjadi objek penelitian adalah rumah tinggal tipe 27 m2 menghadap barat. Rumah ini akan dilakukan renovasi dengan menambahkan ruang dapur dan ruang keluarga dengan luas 18m2. Model bukaan dibagi 3 yaitu :

a) Model 1 bukaan 10\% bagian barat, $10 \%$ bukaan di atap dan 50\% bagian timur

b) Model 2 bukaan $40 \%$ bagian barat, tidak ada bukaan diatap dan 50\% bagian timur

c) Model 3 bukaan 30\% bagian barat, tidak ada bukaan diatap dan 50\% bagian timur 


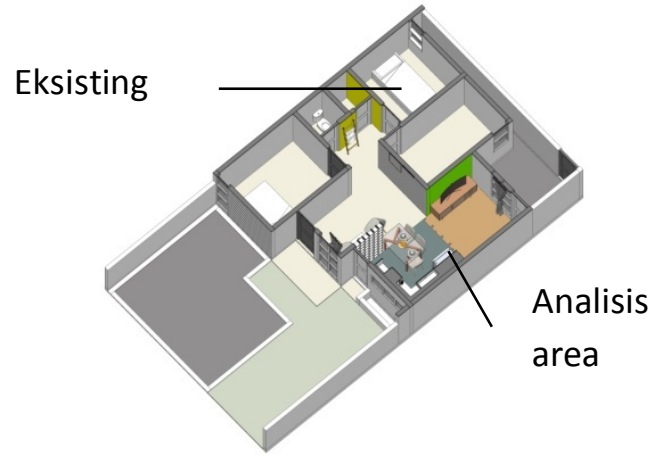

Gambar 1. Model Eksisting

1)

2)

3)

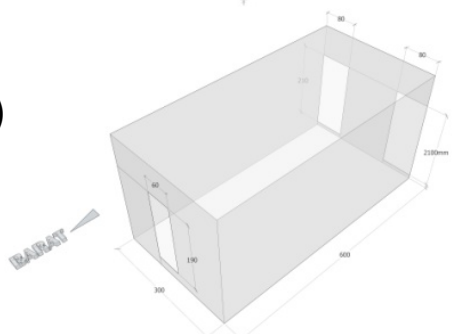

Gambar 2. Model bukaan cahaya

\section{HASIL DAN PEMBAHASAN}

Pencahayaan alami yang akan dilakukan analisis adalah ruang dapur dan ruang keluarga. Ruang keluarga berada bagian sisi timur dan dapur pada sisi bagian barat. Pengukuran dilakukan pada 14.00 WITA pada bulan Agustus dalam kondisi clear sky dan overcast.

Dapur membutuhkan cahaya 250 Lux, sedangkan pada ruang tamu/ruang keluarga 150 Lux. (SNI 03-6197-2000 Konservasi energi pada sistem pencahayaan, 2000). Ruang dapur dan ruang keluarga menjadi 1 ruang sehingga total nilai lux yang dibutuhkan minimal 400 Lux.

Target yang ingin dicapai adalah tipe bukaan cahaya yang dapat memberikan kenyamanan visual dan kenyamanan termal bagi pengguna ruang untuk beraktivitas. Pencahayaan yang sesuai dengan kebutuhan akan memberikan kenyamanan visual. Sedangkan kenyamanan termal berkaitan dengan energi panas ke dalam ruangan. (Parmonangan, 2012).

\section{Analisis Model 1}

Model 1 diberikan bukaan 10\% dari luas dinding pada bagian barat(Dapur), kemudian pada sisi timur diberikan bukaan 50\% (Ruang keluarga) dan ditambahkan bukaan 10\% pada bagian atap.
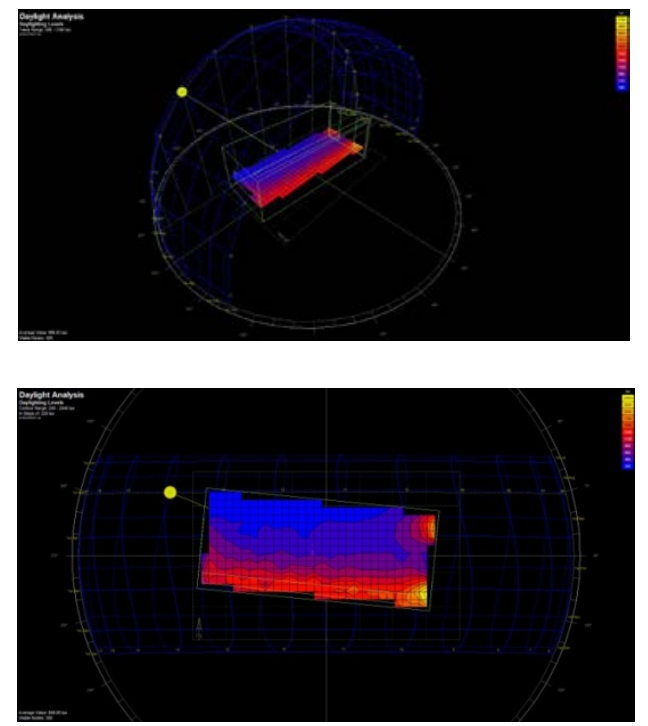

Gambar 3. Analisis Ecotect Analysis pada model 1 kondisi clear sky dan Analisis Ecotect Analysis pada model 1 kondisi overcast

Pada gambar diatas dapat dianalisis bahwa ruang dapur dan ruang keluarga di siang hari pukul 14.00 WITA mendapatkan cahaya dengan nilai ratarata (Average) 998,83 Lux pada kondisi clear sky dan 849 Lux dalam kondisi overcast.

\section{Analisis Model 2}

Model 2 diberikan bukaan 40\% dari luas dinding pada bagian barat(Dapur), 
kemudian pada sisi timur diberikan bukaan 50\% (Ruang keluarga) dan tidak ada bukaan di bagian atap.

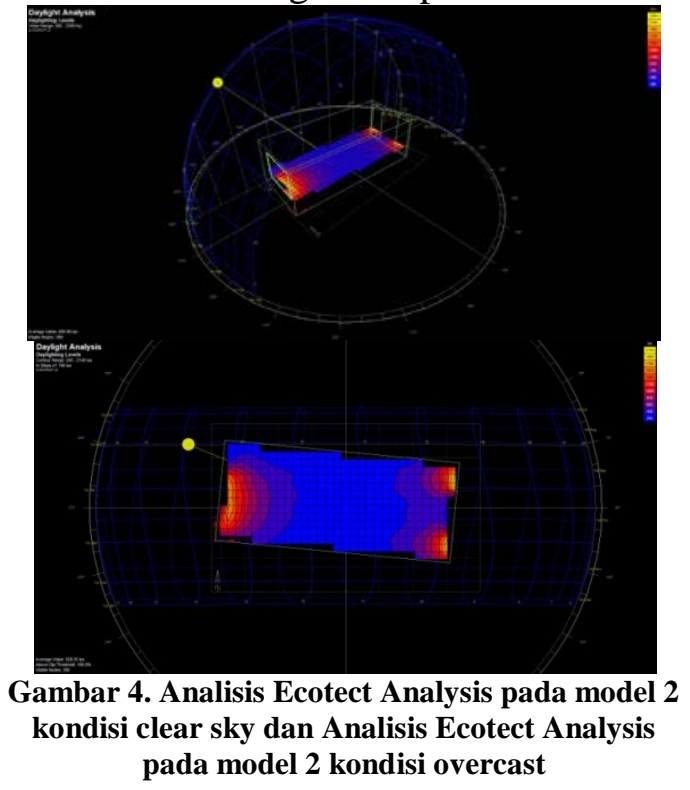

Pada gambar diatas dapat dianalisis bahwa ruang dapur dan ruang keluarga di siang hari pukul 14.00 WITA mendapatkan cahaya dengan nilai ratarata (Average) 656,59 Lux pada kondisi clear sky dan 558,35 Lux dalam kondisi overcast.

\section{Analisis Model 3}

Model 3 diberikan bukaan 30\% dari luas dinding pada bagian barat (Dapur), kemudian pada sisi timur diberikan bukaan 50\% (Ruang keluarga) dan tidak ada bukaan di bagian atap.
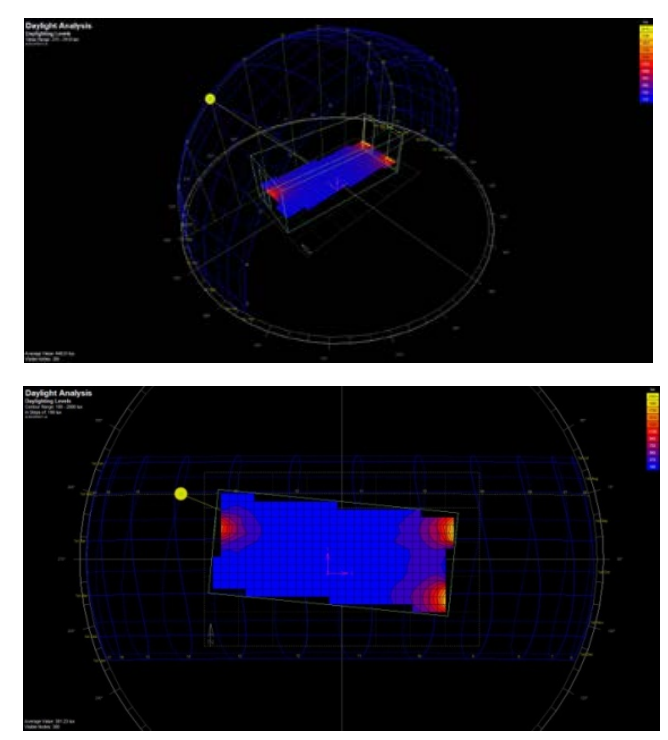

Gambar 5. Analisis Ecotect Analysis pada model 3 kondisi clear sky dan Analisis Ecotect Analysis pada model 3 kondisi overcast

Pada gambar diatas dapat dianalisis bahwa ruang dapur dan ruang keluarga di siang hari pukul 14.00 WITA mendapatkan cahaya dengan nilai ratarata (Average) 448,51 Lux pada kondisi clear sky dan 381,23 Lux dalam kondisi overcast.

\section{Diskusi}

Model 1 suasan ruang sangat terang, bukaan cahaya $10 \%$ dibagian barat tidak memberikan efek meningkatnya suhu didalam bangunan, mengingat bagian dapur terpapar sinar matahari sore. Bukaan cahaya bagian atap sebesar $10 \%$ membantu penerangan dapur dan ruang keluarga sehingga membuat ruang lebih terang. Suhu ruang pada model 1 berada pada batas comfort zone dan penerangan alami lebih optimal ditandai oleh warna merah pada hasil analisis software.
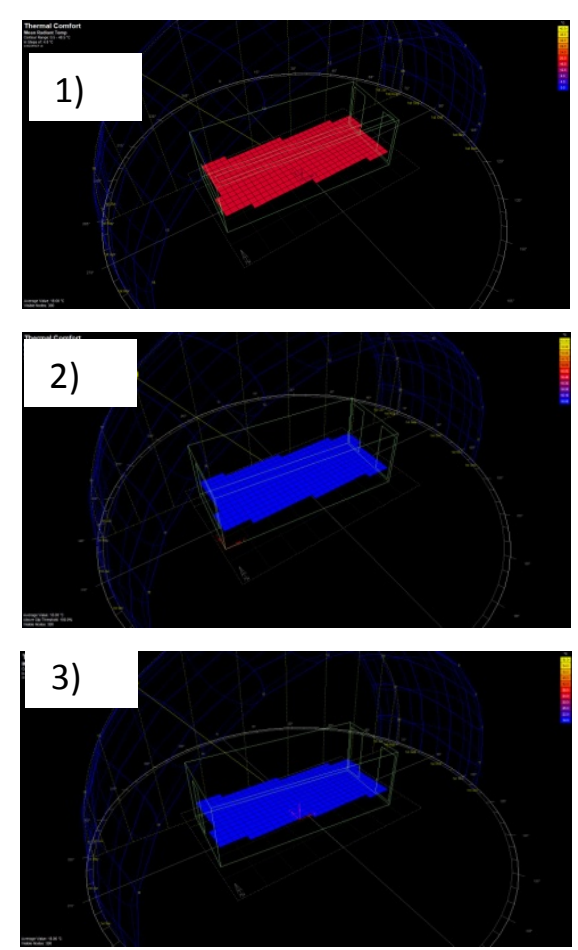

Gambar 6. Analisis Comfort Zone

Model 2 menggunakan bukaan sebesar $40 \%$ membuat ruang terang, bukaan 
cahaya 50 \% pada bagian timur dan tidak terdapat bukaan pada atap. Suhu ruangan berada pada zona comfort zone namun cahaya yang masuk lebih sedikit. Pada kondisi langit overcast ada penurunan nilai cahaya masuk sebesar 100 lux. Bagian dapur akan terpapar sinar matahari sore. Model 3 menggunakan bukaan sebesar 30\% pada bagian barat, bukaan $50 \%$ pada bagian timur dan tidak terdapat bukaan pada atap. Nilai cahaya yang masuk kedalam bangunan tidak mencapai 400 lux pada kondisi overcast .

Dalam mendesain bukaan untuk memasukkan cahaya harus disesuaikan dengan fungsi ruang karena setiap ruang dengan aktivitas tertentu membutuhkan cahaya yang berbedabeda. [4]. Berdasarkan jenis ruang dan pencahayaan, ruang yang akan ditambahkan pada renovasi adalah ruang dapur dan ruang keluarga. Ruang dapur dan ruang keluarga adalah ruangan dengan tingkat aktivitas tinggi dan memerlukan cahaya hangat. (Nurwulandari, 2003).

Pada dasarnya ruang-ruang saling berhubungan dalam satu konteks rumah tinggal. Menurut Ashadi (2017) Rumah harus memenuhi syarat kesehatan dan kenyamanan yang dipengaruhi oleh 3 aspek yaitu pencahayaan, penghawaan dalam ruangan. Pencahayaan Matahari sebagai sumber terbesar yang dapat digunakan sebagai pencahayaan alami pada siang hari. Pencahayaan yang dimaksud adalah penggunaan terang langit dengan ketentuan sebagai berikut:

(1) cuaca dalam keadaan cerah dan tidak berawan; (2) ruangan kegiatan mendapatkan cukup banyak cahaya;(3) ruang kegiatan mendapatkan distribusi cahaya secara merata. Kualitas pencahayaan alami siang hari yang masuk ke dalam ruangan ditentukan oleh:

a) Kegiatan yang membutuhkan daya penglihatan (mata), b) Lamanya waktu kegiatan yang membutuhkan daya penglihatan (mata), c) Tingkat atau gradasi kekasaran dan kehalusan jenis pekerjaan, d) Lubang cahaya minimun persepuluh dari luas lantai ruangan, e) Sinar matahari langsung dapat masuk ke ruangan minimun 1 jam setiap hari, f) Cahaya efektif dapat diperoleh dari jam 08.00 sampai dengan jam 16.00.

Penerangan yang baik dalam ruang perlu memperhatikan beberapa hal yaitu cahaya alami, kuat penerangan, kualitas cahaya, daya penerangan, pemilihan dan perletakan lampu. Pencahayaan alami dapat membantu penerangan buatan dalam ruang dengan ketentuan dalam penataan pencahyaan (Hakim, 2006).

Model 1, model 2 dan model 3 pada dasarnya telah memenuhi persyaratan kualitas pencahayaan alami siang hari. Model 1 memiliki kualitas sangat terang, model 2 terang, dan model 3 jika kondisi cuaca cerah (clear sky) masih cukup cahaya namun jika kondisi overcast perlu bantuan pencahayaan buatan. Model 1 memberikan kenyamanan secara visual dan spatial comfort (kenyamanan ruang) sehingga aktivitas tidak terganggu pada saat kondisi cerah maupun mendung.

Rumah dengan bukaan ke arah timur akan mendapat sinar matahari pagi berwarna kuning lembut, yang menyehatkan tubuh. Ruang tidur, ruang makan, dan dapur sangat baik jika menghadap timur. Pagi hari pukul 7 sampai pukul 10 adalah waktu terbaik untuk menikmati cahaya matahari. Sebaliknya rumah yang berorientasi ke barat akan mendapat cahaya matahari sore yang kuat dan keras. Filter seperti sunshade bisa digunakan untuk menghindari paparan langsung sinar matahari dari barat [5].

Pada Model 1 bukaan bagian barat sebesar $10 \%$ sehingga tidak diperlukan sun shade sedangkan pada model 2 bukaan sebesar 40\% sehingga diperlukan sun shade untuk mengurangi paparan sinar matahari sore. 


\section{KESIMPULAN}

Ruang dapur dan ruang keluarga merupakan ruang dengan tingkat aktivitas tinggi sehingga memerlukan penerangan yang optimal. Tingkat pencahayaan yang paling optimal adalah tipe bukaan model 1 yaitu dengan bukaan 10\% bagian barat, 10\% bukaan bagian atap, dan $50 \%$ bagian timur. Tingkat pencahayaan yang dihasilkan adalah 998,58 lux pada kondisi clear sky dan 849 lux kondisi overcast. Pencahayaan yang dihasil pada model 1 diharapkan dapat menjadi strategi perencanaan rumah tinggal dengan mengoptimalkan masuknya cahaya matahari dan dapat membantu penerangan rumah eksisting.

\section{UCAPAN TERIMA KASIH}

1) Terima kasih kepada Politeknik Negeri Samarinda sebagai institusi pendidikan yang memberikan fasilitas dalam penelitian ini.

2) Terima kasih kepada rekan penulis yang telah meluangkan waktu untuk diskusi dalam menyelasaikan tulisan ini.

3) Terima kasih kepada jajaran P3M Politeknik Negeri Samarinda yang telah menjadi media konsultasi dan pengawas proses penulisan tulisan ini.

\section{DAFTAR PUSTAKA}

[1] Ashadi, Anisa, \& Nelfiyanti. (2017). Konsep Disain Rumah Sederhana Tipe Kecil Dengan Mempertimbangkan Kenyamanan Ruang. NALARs, 16(1), 1-14. https://doi.org/10.24853/nalars.16.1 .1-14

[2] Ashadi, Nelfiyanti, \& Anisa. (2016). Pencahayaan dan ruang gerak efektif sebagai indikator kenyamanan pada rumah sederhana sehat yang ergonomis (Studi Kasus Rumah Sederhana Sehat di Bekasi). NALARs, 15(1), 35. https: //doi.org /10.24853/nalars.15.1.35-44
[3] Gw, O. R., \& Kusumo, B. S. (2011). Studi evaluasi pencahayaan alami pada gedung kuliah bersama iii universitas muhammadiyah malang ode. Media Teknik Sipil, 9(1), 50-60.

[4] Hakim, R. (2006). Arsitektur Lanskap. Penerbit Bumi Aksara.

[5] Nurwulandari. (2003). Rumah Hemat Energi. Serial Rumah, Gramedia.

[6] Parmonangan, M. (2012). Pencahayaan Alami dalam Arsitektur. Yogyakarta: Penerbit Andi.

[7] Setiawan, B., \& Hartanti, G. (2014). Pencahayaan buatan pada pendekatan teknis dan estetis untuk bangunan dan ruang dalam. HUMANIORA, 5(9), 1222-1233.

[8] Suprapto, \& Sodikin. (2014). Daylighting untuk perumahan sederhana. In Prosiding Seminar Nasional Aplikasi Sains \& Teknologi (SNAST) (Vol. 3, pp. 211-216). https://doi.org/1979911X

[9] Vidiyanti, C. (2016). Strategi peningkatan pencahayaan alami pada ruang minim bukaan samping melalui perangkat pencahayaan atas. Vitruvian, Jurnal Arsitektur,Bangunan \& Lingkungan, 6, 25-32.

[10](2000). SNI 03-6197-2000 Konservasi energi pada sistem pencahayaan. 
POLITEKNOLOGI VOL. 19 NO. 1 JANUARI 2020

Tabel 1.

SNI 03-6197-2000 Konservasi energi pada sistem pencahayaan

\begin{tabular}{|c|c|c|c|c|c|}
\hline \multirow[t]{2}{*}{ Fungsi ruangan } & \multirow{2}{*}{$\begin{array}{c}\text { Tingkat } \\
\text { pencahayaan } \\
\text { (Lux) }\end{array}$} & \multirow{2}{*}{$\begin{array}{c}\text { Kelompok } \\
\text { renderasi } \\
\text { warna }\end{array}$} & \multicolumn{3}{|c|}{ Temperatur warna } \\
\hline & & & $<3300 \mathrm{~K}$ & $\begin{array}{c}\text { Cool white } \\
\text { 3300K-5300K }\end{array}$ & $\begin{array}{l}\text { Daylight } \\
>5300 \mathrm{~K}\end{array}$ \\
\hline \multicolumn{6}{|l|}{ Rumah tinggal } \\
\hline Teras & 60 & 1 atau 2 & * & $*$ & \\
\hline Ruang tamu & $120-150$ & 1 atau 2 & & * & \\
\hline Kamar tidur & $120-250$ & 1 atau 2 & * & * & \\
\hline Kamar mandi & 250 & 1 atau 2 & & * & $*$ \\
\hline Dapur & 250 & 1 atau 2 & * & $*$ & \\
\hline
\end{tabular}

Tabel 2.

Tabel hasil analisis

\begin{tabular}{cccccc}
\hline \multicolumn{2}{c}{ Model 1 } & \multicolumn{2}{c}{ Model 2 } & \multicolumn{2}{c}{ Model 3 } \\
\hline Clear Sky & Overcast & Clear Sky & Overcast & Clear Sky & Overcast \\
$\mathbf{9 9 8 , 8 3 ~ L u x ~}$ & 849 Lux & 656,59 Lux & 558,35 Lux & 448,51 Lux & 381,23 Lux \\
\hline
\end{tabular}


Ibayasid dkk, Pemanfaatan Pencahayaan Alami... 